\title{
IMPLEMENTASI APLIKASI USER MANAGER MIKROTIK BERBASIS WEB PADA SMA NEGERI 7 MATARAM
}

\author{
Moh. Subli ${ }^{1}$, Lalu Moh. Nurkholis ${ }^{2}$ \\ Universitas Teknologi Mataram ${ }^{1,2}$ \\ subli.kerta@gmail.com ${ }^{1}$, lalunurkholis1967@gmail.com ${ }^{2}$
}

\begin{abstract}
Abstrak - Permasalahan yang sering dialami dalam jaringan hotspot adalah jaringan lambat dan sinyal lemah. Permasalahan ini diakibatkan karena belum adanya user manager yang mengatur bandwidth dan jumlah user yang ada. Permasalahan ini sering diselesaikan dengan cara melakukan perbaikan sederhana dan melakukan konfigurasi ulang setiap terjadi masalah. Namun, pada jaringan hotspot yang sudah kompleks, pengkonfigrasian yang ulang akan memakan waktu yang lama serta menghabiskan banyak biaya. Oleh karena itu, sebuah jaringan hotspot memerlukan aplikasi user manager untuk memanajemen bandwidth dan manajemen user, sehingga dapat mengatur lalu lintas data dengan cepat dan efisien. Dalam penelitian ini, peneliti membuat implementasi aplikasi user manager mikrotik berbasis web untuk memanejemen bandwith dan user. Implementasi aplikasi user manager mikrotik berbasis web dibuat untuk mempermudah dalam pengaturan jaringan hotspot yang sebelumnya hanya bisa dilakukan lewat winbox saja, tentunya ini dilakukan untuk memaksimalkan bandwidth yang ada, mengatur jumlah user, dan batas waktu akses. Dari hasil penelitian dapat diketahui bahwa penambahan aplikasi user manager dapat mengatur lalu lintas data atau pertukaran data menjadi lebih baik dan pemakaiannya lebih optimal.
\end{abstract}

Kata Kunci: Jaringan, Hotspot, Mikrotik Berbasis Web, Bandwidth, User.

\section{LATAR BELAKANG}

Jaringan komputer bukanlah sesuatu yang baru pada saat ini. Hampir disetiap perusahaan, instansi, sekolah, terdapat jaringan komputer sebagai sarana untuk memperoleh informasi. Jaringan komputer adalah sekelompok komputer otonom yang saling berhubungan antara yang satu dengan yang lainya, dan menggunakan suatu protokol komunikasi melalui media komunikasi sehingga dapat saling berbagi dan bertukar informasi. Pada sebuah teknologi jaringan diperlukan suatu device yang dapat melakukan manajemen antar jaringan yang ada. Device tersebut disebut dengan router.

Permasalahan yang sering muncul di SMAN Negeri 7 Mataram berhubungan dengan akses internet adalah koneksi internet menjadi lambat dan putus-putus pada saat melakukan download maupun upload, bahkan kadang tidak bisa melakukan akses internet sama sekali, dan juga permasalahan penambahan user yang kurang efektif, sehingga diperlukannya aplikasi user manager untuk mempermudah kinerja administrator dalam mengatasi hal-hal tersebut.

Dengan memanajemen user menggunakan router mikrotik, maka koneksi internet menjadi lancar karena bandwidth yang dimiliki telah dibagi ke masing-masing user atau client sesuai dengan kebutuhan bandwidth yang dibutuhkan masingmasing user pengguna hotspot. Hal ini memudahkan administrator dalam memantau akses internet yang dilakukan oleh masing - masing user karena telah dilakukan manajemen bandwidth tersebut. Tampilan yang sederhana juga membuat administrator lebih mudah untuk menggunakan aplikasi user manager tersebut. Oleh karena itu dalam penelitian ini penulis mengambil judul "implementasi aplikasi user manager mikrotik berbasis web pada SMAN 7 Mataram".

\section{LANDASAN TEORI}

\section{A. Jaringan Komputer}

Internet yang popular saat ini merupakan suatu jaringan komputer raksasa yang saling terhubung dan dapat berinteraksi. Hal ini dapat terjadi karena adanya perkembangan teknologi jaringan yang sangat pesat, sehingga dalam beberapa tahun saja jumlah pengguna komputer yang tergabung dalam internet telah berlipat ganda. Karena itu jaringan komputer bukan suatu yang baru saat ini dan hampir di setiap perusahaan maupun instansi terdapat jaringan komputer. Saat ini banyak orang menggunakan internet dalam pekerjaan sehingga makin berkembang berbagai aplikasi, media, dan cara-cara mudah mengakses internet. Salah satunya yaitu hotspot yang banyak digemari karena pemakaiannya mudah dan lebih murah dibandingkan internet berlangganan pada suatu ISP paket perorangan. Hal ini karena hospot tidak membutuhkan kabel untuk sharing data dan

Implementasi Aplikasi User Manager Mikrotik Berbasis Web Pada SMA Negeri 7 Mataram 
mengandalkan media transmisi wireless (nirkabel) dengan sinyal [1].

Wi-Fi merupakan singkatan dari Wireless Fidelity yaitu sebuah media penghantar komunikasi data tanpa kabel yang bisa digunakan untuk komunikasi atau mentransfer program dan data dengan kemampuan yang sangat cepat. Wi-Fi juga dapat diartikan teknologi yang memanfaatkan peralatan elektronik untuk bertukar data dengan menggunakan gelombang radio (nirkabel) melalui sebuah jaringan komputer termasuk koneksi. Namun kenyataan di lapangan menunjukkan bahwa media/fasilitas untuk mengakses jaringan $\mathrm{Wi}-\mathrm{Fi}$ belum tersedia sebagaimana mestinya sehingga kepuasan pemustaka untuk mengakses informasi online belum terpenuhi dengan baik [2].

\section{B. Mikrotik}

Mikrotik router OS adalah sistem operasi dan perangkat lunak yang dapat menjadikan komputer biasa sebagai router network yang handal, mencakup berbagai fitur untuk IP network dan jaringan wireless. Mikrotik dapat digunakan dalam dalam bentuk perangkat keras dan perangkat lunak yang dapat diinstal kedalam PC [1].

Mikrotik RouterBoard adalah sebuah board router yang di dalamnya sudah terinstal Mikrotik RouterOS, yaitu sistem operasi berbasis Linux yang didalamnya terdapat fitur layanan hotspot. Pada Mikrotik ini terdapat fitur tambahan yaitu User Manager yang merupakan web interface yang user friendly untuk manajemen hotspot [3].

Mikrotik didesain untuk memberikan kemudahan bagi penggunanya, dapat diakses melalui windows application (WinBox) dapat dilihat pada gambar 3 , mencakup berbagai fitur seperti firewall dan nat, routing, hotspot, DNS server, DHCP server, management bandwitch, web proxy serta mampu menyaring akses di internet dan dapat memblokir website, membagi bandwidth internet kepada client [4].

\section{Bandwith}

Bandwidth merupakan suatu ukuran dari banyaknya informasi yang dapat mengalir dari suatu tempat ke tempat lain dalam suatu waktu tertentu [5]. Bandwidth dapat dipakai untuk mengukur baik aliran data analog maupun aliran data digital. Sekarang bandwidth lebih banyak digunakan untuk mengukur aliran data digital. Satuan yang dipakai untuk bandwidth adalah bits persecond atau sering disingkat sebagai bps. Bit atau binery digit adalah basis angka yang terdiri dari angka 0 dan 1 . Satuan ini menggambarkan seberapa banyak bit (angka 0 dan 1) yang dapat mengalir dari satu tempat ketempat yang lain dalam setiap detik melalui suatu media.

Manajemen bandwidth merupakan teknik pengelolaan jaringan sebagai usaha untuk memberikan performa jaringan yang adil dan memuaskan. Manajemen bandwith juga digunakan untuk memastikan bandwidth yang memadai untuk memenuhi kebutuhan trafik data dan informasi serta mencegah persaingan antara aplikasi. Manajemen bandwidth menjadi hal mutlak bagi jaringan multi layanan, semakin banyak dan bervariasinya aplikasi yang dapat dilayani oleh suatu jaringan akan berpengaruh pada penggunaan link dalam jaringan tersebut. Link-link yang ada harus mampu menangani kebutuhan user akan aplikasi tesebut bahkan dalam keadaan kongesti sekalipun [6].

Pengunaan bandwidth pada jaringan internet saat ini sering kali kurang dimanfaatkan secara optimal. Hal ini dapat disebabakan karena adanya tarik menarik kapasitas bandwidth antara pengguna yang menggunakan internet untuk keperluan browsing maupun untuk download ataupun upload. Queue Tree berfungsi untuk mengimplementasikan fungsi yang lebih kompleks dalam limitbandwidth pada mikrotik dimana penggunaan packet mark nya memiliki fungsi yang lebih baik. Digunakan untuk membatasi satu arah koneksi saja baik itu download maupun upload [7].

\section{Website}

Perkembangan Teknologi Informasi (TI) berkembang sangat pesat. Pesatnya perkembangan $\mathrm{TI}$ menjadikan teknologi internet sebagai alat komunikasi utama yang sangat diminati oleh masyarakat. Dengan adanya teknologi internet akan mempermudah dan mempercepat pencarian informasi, salah satu sumber informasi yang dapat dijadikan rujukan adalah website [8].

Website adalah kumpulan dari halamanhalaman situs, yang terangkum dalam sebuah domain atau subdomain, yang tempatnya berada di dalam World Wide Web ( WWW ) di dalam internet [9], website juga dapat diartikan sebagai sebuah halaman yang berisi data, baik data text, gambar, suara dan lainya yang dapat diakses secara online. ada banyak model pengembangan sistem yang bisa dimanfaatkan untuk membangun website salah satunya model Prototyping.

Informasi khususnya pada bidang website yang saat ini menjadi media informasi yang

\section{Implementasi Aplikasi User Manager Mikrotik Berbasis Web Pada SMA Negeri 7 Mataram}


menawarkan berbagai kemudahan dalam menyajikan informasi. Kecepatan dan kenyamanan merupakan nilai positif adanya internet [10].

Website adalah apa yang anda lihat via browser, sedangkan yang disebut web sebenarnya adalah sebuah aplikasi web, karena melakukan action tertentu dan membantu anda melakukan kegiatan tertentu [11].

\section{E. PHP dan XAMPP}

PHP singkatan dari Hypertext Preprocessor yang merupakan server-side programing, yaitu bahasa pemrograman yang diproses di sisi server [12].

Fungsi utama PHP dalam membangun website adalah untuk melakukan pengolahan data pada database. Data website akan dimasukkan ke database, diedit, dihapus, dan ditampilkan pada website yang diatur oleh PHP.

PHP berasal dari kata Hypertext Preprocessor, yaitu bahas pemrograman universal untuk penanganan pembuatan dan pengembangan sebuah situs web dan bisa digunakan bersamaan dengan HTML.

Xampp adalah sebuah aplikasi yang dapat menjadikan komputer kita menjadi sebuah server. Kegunaan Xampp ini untuk membuat jaringan local sendiri dalam artian kita dapat membuat website secara offline untuk masa coba-coba di komputer sendiri [13].

Jadi fungsi dari Xampp server itu sendiri merupakan server website kita untuk cara memakainya. Disebut server karena dalam hal ini komputer yang akan kita pakai harus memberikan pelayanan untuk mengakseskan web, untuk itu komputer kita harus menjadi server. Dapat disimpulkan xampp adalah aplikasi tools untuk menyediakan paket lunak yang berisi konfigurasi Web Server, Apache, PHP, MySQL untuk membantu kita dalam proses pembuatan aplikasi web yang menyatu menjadi satu sehingga memudahkan kita dalam membuat program web [14].

Program PHP dan MySQL yang ada sekarang sudah dibundling dalam satu paket program bernama XAMPP. XAMPP merupakan paket PHP berbasis Open Source. XAMPP mengkombinasi beberapa paket perangkat lunak berbeda ke dalam satu paket. Paket yang disediakan antara lain adalah Apache, MySQL, PHP, FilZilla FTP Server, phpMyAdmin, dan lain-lain [15].

\section{ANALISA SISTEM (JARINGAN)}

\section{A. Analisa Permasalahan}

SMA Negeri 7 Mataram merupakan salah satu Sekolah Menengah Atas Negeri yang ada di Mataram, yang diresmikan pada tanggal 31 Agustus 2004 dan merupakan salah satu sekolah favorit di Mataram. Sekolah ini memiliki beberapa ruangan yang terhubung dengan akses internet di antaranya laboratorium komputer, ruang BK, ruang tata usaha, ruang wakasek, ruang guru, dan perpustakaan.

SMA Negeri 7 Mataram saat ini sudah terkoneksi ke internet menggunakan ISP dari modem indihome yang memiliki bandwidth sebesar 20Mbps. Permasalahan yang ada di sekolah ini adalah banyaknya siswa, guru maupun staf tata usah yang ingin membuat user baru agar bisa terhubung oleh hotspot SMAN 7 Mataram, dan agar pengaturan bandwith yang berbeda antara guru dan siswa.

Agar memudahkan pihak admin sekolah untuk mengontrol jaringan hotspot, menambahkan user dan mengatur masingmasing bandwith dengan mudah pada sekolah ini yang akan digunakan untuk melaksanakan kegiatan mengajar, pendidikan dan kegiatan lain sebagainya. Maka untuk menyelesaikan permasalahan tersebut. Setelah menganalisa permasalahan tersebut, cara untuk menyelesaikan permasalahan tersebut dengan cara membuat aplikasi user manager agar memudahkan admin pihak sekolah untuk mengontrol jaringan hotspot, menambahkan user dan mengatur masing-masing bandwith yang berbeda antara guru dan siswa. pembagian bandwidth kemasing-masing user sesuai dengan kebutuhannya. Pengaturan bandwidth yang dilakukan yaitu memisahkan antara traffict download-upload dan browsing agar koneksi yang didapat menjadi stabil dan lancar.

\section{B. Skema Jaringan}

Jaringan yang ada di SMA Negeri 7 Mataram sudah tersedia dibeberapa ruangan yang digunakan untuk kegiatan pendidikan. Fasilitas jaringan yang dimiliki oleh sekolah ini yaitu memiliki tiga modem indihome wireless yang diletakan di tiga ruangan diantaranya yaitu satu diruanga Laboratorium komputer dengan bandwidth 20Mbps, satu diruang guru dengan bandwidth 20Mbps dan Satu diruang perpustakaan dengan bandwidth 20Mbps.

Masing-masing modem ini akan dihubungkan langsung ke beberapa komputer dimasing-masing ruangan dengan kabel dan jaringan wifi yang ada dimasing-masing modem 
digunakan untuk pegawai dan siswa yang ingin mendapatkan akses internet. Berikut skema jaringan di SMA Negeri 7 Mataram.

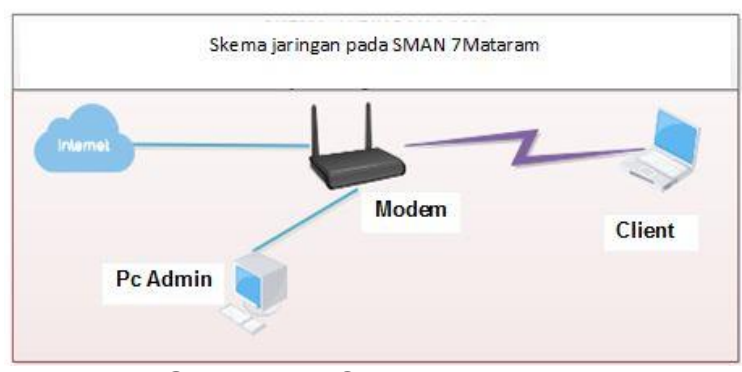

Gambar 1. Skema Jaringan

\section{Analisa Kebutuhan}

\section{Analisa Kebutuhan Perangkat (Software dan Hardware)}

Tabel 1. Analisa Kebutuhan Perangkat

\begin{tabular}{|c|c|c|c|}
\hline No. & Nama Bahan & Spesifikasi & Jumlah \\
\hline 1 & Admin & $\begin{array}{l}\text { 1. Processor Intel(R) core I } 3 \\
\text { 2. Ram } 4 \mathrm{~Gb} \\
\text { 3. Hardisk } 500 \mathrm{gb} \\
\text { 4. LAN Card } \\
\end{array}$ & 1 Unit \\
\hline 2 & Router & $\begin{array}{l}\text { 1. Nama: MikrotikRB750r2 (hEX- } \\
\text { Lite) } \\
\text { 2. CPU QCA9531-BL3A-R } \\
850 \mathrm{MHz} \\
\text { 3. Main Storage } 16 \mathrm{MB} \\
\text { 4. Ram } 64 \mathrm{MB} \\
\text { 5. Lan Port } 5 \\
\text { 6. Operating System RouterOS } \\
\text { 7. RoterOS License Level } 4\end{array}$ & 1 Unit \\
\hline 3 & Xampp & Versi 3.3 .3 & Aplikasi \\
\hline 4 & Modem & - & 1 Unit \\
\hline 5 & Kabel UTP & Cat 5 & 2 Unit \\
\hline 6 & $\begin{array}{l}\text { Sistem } \\
\text { Operasi }\end{array}$ & Windows 7 admin & OS \\
\hline 7 & Uc browser & & Aplikasi \\
\hline 8 & Winbox & Versi 3.18 & Aplikasi \\
\hline 9 & Virtual Box & Versi 5.2 .0 & Aplikasi \\
\hline 10 & Notepad ++ & Versi 7.5.6 & Aplikasi \\
\hline
\end{tabular}

2. Analisa Kebutuhan IP Address (Perhitungan Subnetting dan Sebaran IP Address)

IP Address untuk Ether1 192.168.1.1. IP untuk Ether2 yaitu 172.16.2.2 dan subnetmask 255.255.255.252 dengan maksimal 1 PC (Admin) yang dapat terhubung. Pada Ether3 diberi IP 192.168.20.1 dan subnetmask 255.255.255.126 dengan maksimal 126 user yang dapat terhubung. Berikut table kebutuhan IP Address.

Tabel 2. Analisa Kebutuhan IP Address

\begin{tabular}{|c|l|l|l|l|l|}
\hline $\begin{array}{c}\text { No } \\
\text { }\end{array}$ & $\begin{array}{c}\text { Perangk } \\
\text { at }\end{array}$ & Interface & IP Address & \multicolumn{1}{|c|}{$\begin{array}{c}\text { Subnet } \\
\text { Mask }\end{array}$} & Gateway \\
\hline 1 & $\begin{array}{l}\text { Modem/ } \\
\text { ISP }\end{array}$ & - & 192.168 .1 .1 & $\begin{array}{l}255.255 .255 \\
0\end{array}$ & - \\
\hline 2 & Mikrotik & Ether1 & 192.168 .16 .1 & $\begin{array}{l}255.255 .255 \\
0\end{array}$ & - \\
\hline 3 & Admin & Ether2 & 172.16 .16 .2 & $\begin{array}{l}255.255 .255 \\
252\end{array}$ & 172.16 .16 .1 \\
\hline 4 & Hotspot & Ether 3 & 192.168 .20 .1 & $\begin{array}{l}255.255 .255 \\
126\end{array}$ & - \\
\hline
\end{tabular}

\section{Perancangan Jaringan}

\section{Topologi Jaringan}

Dalam penelitian ini akan merancang sebuah aplikasi user manager hotspot pada Laboratorium komputer yang ada pada SMA Negeri 7 Mataram, dimana japlikasi tersebut merupakan pengembangan dari aplikasi winbox. Topologi yag akan dibangun pada SMA Negeri Mataram yaitu:

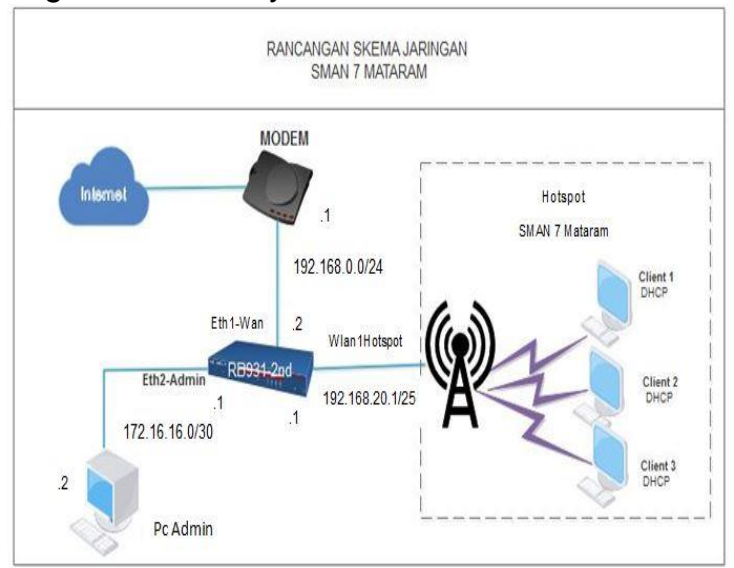

Gambar 2. Skema Jaringan

2. Infrastruktur Jaringan

Mikrotik

Digunakan sebagai router untuk menghubungkan jaringan dari modem sebagai ISP di ether1, ether3 untuk menyebarkan paket data secara wireless. Ether2 dihubungkan ke server (admin) untuk mengkoneksikan antara aplikasu user manager dan komputer admin

\section{Admin}

Dihubungkan ke ether2 pada mikrotik untuk mengontrol jaringan hotspot sehingga jaringan bisa terkontrol dengan baik.

\section{Modem}

Sebagai ISP yang akan memberikan paket data sesuai dengan bandwidth yang ada ke ether1 mikrotik. Diperangkat mikrotik akan diatur penerimaan IP-nya, yaitu menggunkan DHCP Client agar mikrotik mendapat IP otomatis dari modem.

\section{Kabel UTP}

Digunakan untuk menghubungkan perangkat jaringan hotspot yaitu menghubungkan modem dengan port1 pada mikrotik, menghubungkan port2 pada mikrotik ke server (admin), dan menghubungkan port3 pada mikrotik ke access Point.

\section{Winbox}

Winbox sangat mudah digunakan dan mudah dalam pengkonfigurasiannya. Aplikasi ini digunakan untuk mengkonfigurasi jaringan hotspot yang telah dibuat skemanya. 


\section{Pemrograman PHP}

Digunakan untuk mengimplentasi aplikasi user_manager yang akan digunakan untuk mengontrol jaringan hotspot.

\section{E. Desain Interface}

Aplikasi user manager yang dirancang pada SMAN 7 diantaranya ada halaman admin, memiliki hak akses untuk input data, edit data, dan hapus data. Berikut adalah desain interface dari halaman user manager yang ada pada SMAN 7 Mataram:

Desain Menu Login

Halaman login berisi nama dan password yang akan digunakan untuk membuka aplikasi user manager.

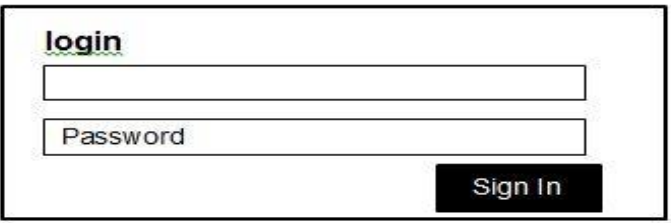

Gambar 3. Desain Menu Login

\section{Desain Menu Home}

Halaman home terdiri dari beberapa menu diantaranya seperti dashboard, master, user hotspot, user profile dan about. Halaman home ini diperuntukan admin untuk mengontrol jaringan hotspot pada SMAN 7 Mataram.

\begin{tabular}{|l|l|l|l|l|}
\hline \multicolumn{4}{|l|}{ Selamat Datang } \\
\hline Dashboard & Master & User Hotspot & User Profile & About \\
\hline Selamat Datang \\
\hline \multicolumn{4}{|l}{} \\
\hline SMAN 7 Mataram \\
\hline
\end{tabular}

Gambar 4. Desain Menu Home

\section{IMPLEMENTASI}

A. Koneksi ke Mikrotik

Sebelum aplikasi siap untuk digunakan pertama admin harus mengkoneksikan aplikasi user manager dengan perangkat mikrotik.

Berikut langkah-langkahnya:

> Pastikan api pada mikrotik berwarna hijau dapat dilihat di menu IP - Service

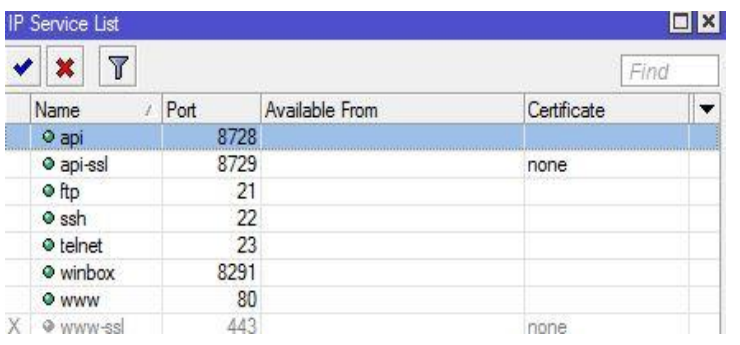

Gambar 5. File Api pada Winbox

Ubah IP Config dengan menggunakan IP pada Ether2 - Admin

\begin{tabular}{|c|c|c|}
\hline \multicolumn{2}{|c|}{ 罗 config.php $\mathbf{X}$} & 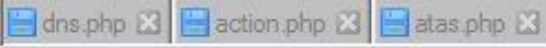 \\
\hline 1 & $\boxminus<? \mathrm{p}$ & \\
\hline 2 & err & or_reporting $(\sim \mathrm{E}$ _NOTICE $)$; \\
\hline 3 & $/ / \mathrm{M}$ & asulkan IP Address Mikrotik \\
\hline 4 & $\$ I P$ & ADDRESS $=" 172 \cdot 16 \cdot 16.1 "$ \\
\hline 5 & $/ / \mathrm{M}$ & emangqiA MIKROTIK API \\
\hline 6 & inc & lude "lib/routeros_api.pha"; \\
\hline 7 & $/ / M$ & embuat Object API Mjkrotik \\
\hline 8 & $\$ A P$ & $\mathrm{I}=$ new routeros_api () \\
\hline 9 & \$AP & I->debug=false \\
\hline 10 & $L_{?>}$ & \\
\hline
\end{tabular}

\section{Gambar 6. IP Config}

Ubah IP pada laptop disesuaikan dengan IP Ether2 - Admin

lou can get IP settings assigned automatically if your network supports his capability. Otherwise, you need to ask your network administrator or the appropriate IP settings.

Obtain an IP address automatically
Use the following IP address:
\begin{tabular}{l} 
IP address: \\
Subnet mask: \\
Default gateway: \\
\hline $255,255 \cdot 255,0$ \\
\hline $172,16,16,16 \cdot 2$ \\
\hline
\end{tabular}

Gambar 7. IP Laptop

\section{B. Manajemen Bandwith}

Dengan aplikasi user manager admin dapat dengan mudah membatasi kecepatan upload dan download antara siswa dan guru. Berikut akan dijelaskan bagaimana cara untuk membatasi kecepatan upload dan download antara siswa dan guru:

\section{$>$ Login Aplikasi User Manager}

Admin login terlebih dahulu ke aplikasi User manager

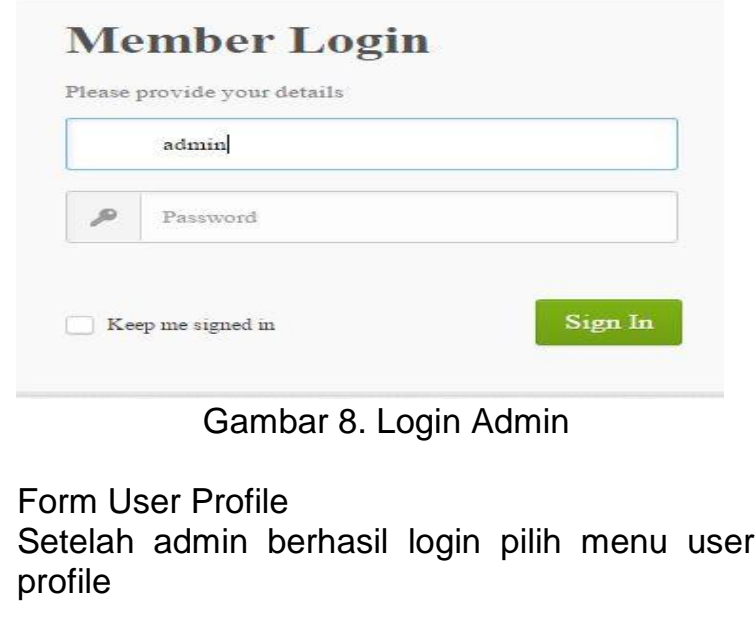

Implementasi Aplikasi User Manager Mikrotik Berbasis Web Pada SMA Negeri 7 Mataram 


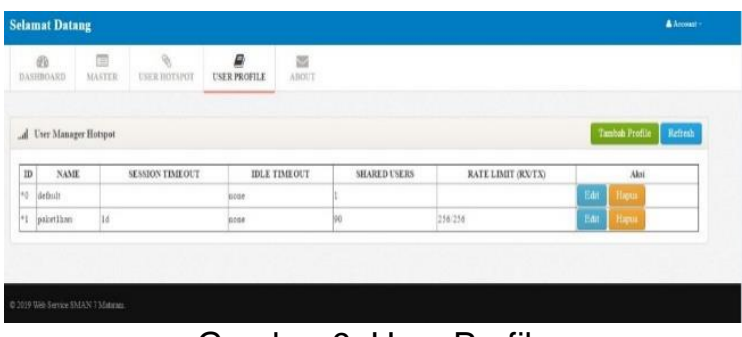

Gambar 9. User Profile

Tambah Profile

Kemudian admin mengklick button tambah profile. Isisikan nama, session timeout, shared user, rate limit dan klick button simpan.

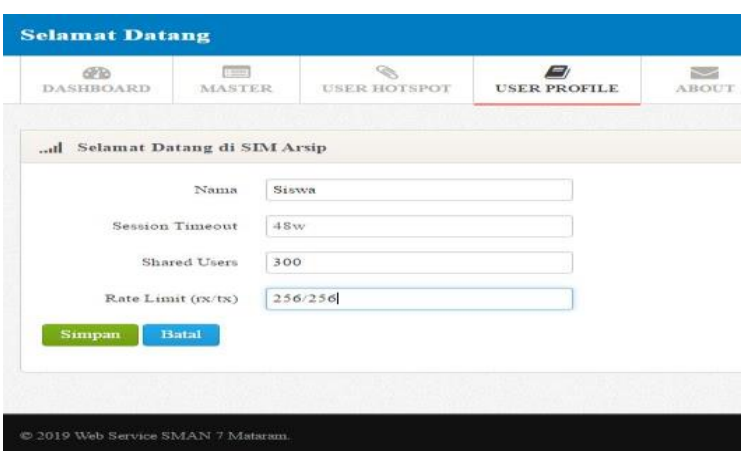

Gambar 10. Tambah Profile

Setelah berhasil maka akan tersimpan di halaman user profile. Bandwith untuk siswa 256/256 dan untuk guru 512/512. Admin juga dengan mudah mengubah maupun menghapus user profile yang sudah dibuat.

Berikut adalah user profile yang telah tersimpan:

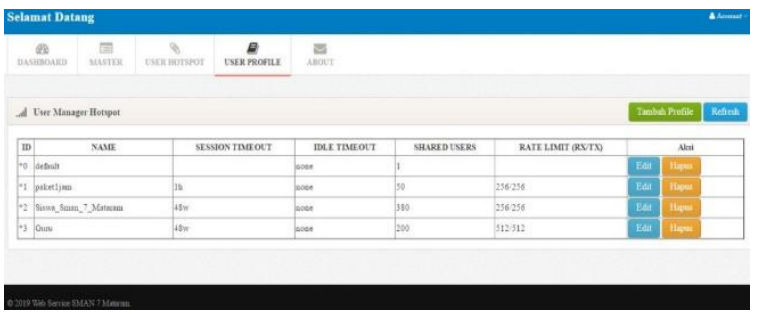

Gambar 11. Menyimpan User Profile

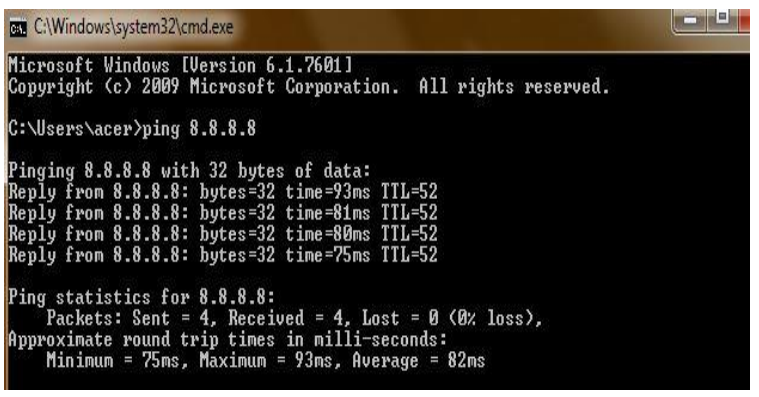

Gambar 12. Test Ping Google
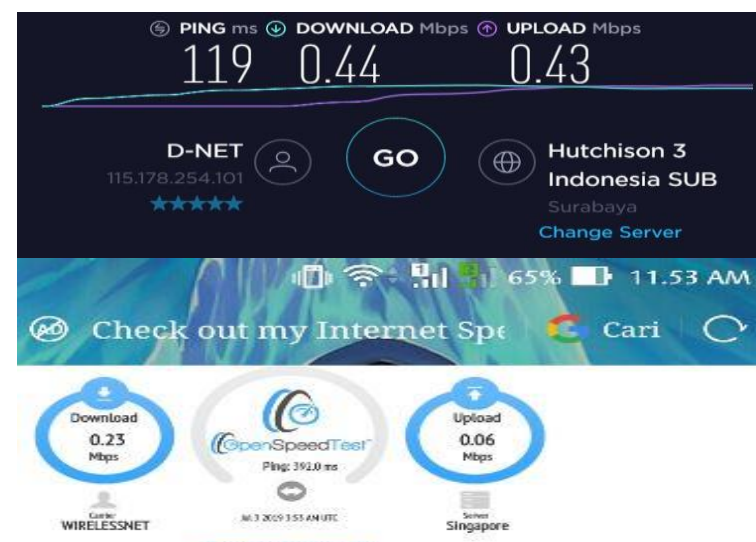

YOUR RESLET D PMGE USae

ine

Gambar 13. Speedtest Untuk Siswa dan Guru

\section{Manajemen User}

Dengan aplikasi user manager admin dapat dengan mudah menambahkan user hotspot bagi siswa maupun guru yang ingin membuat hotspot.

$>$ Login Aplikasi User Manager

Admin login terlebih dahulu ke aplikasi User manager

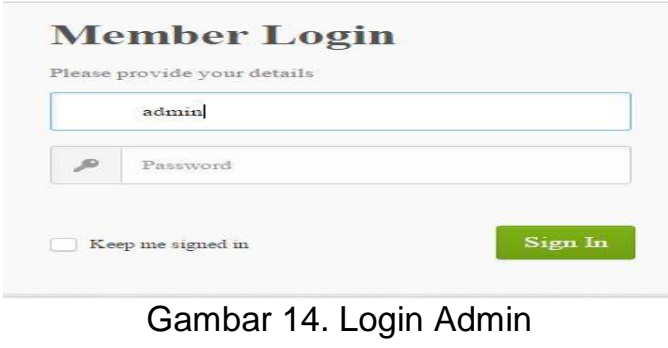

Form User Hotspot

Setelah admin berhasil login pilih menu user hotspot

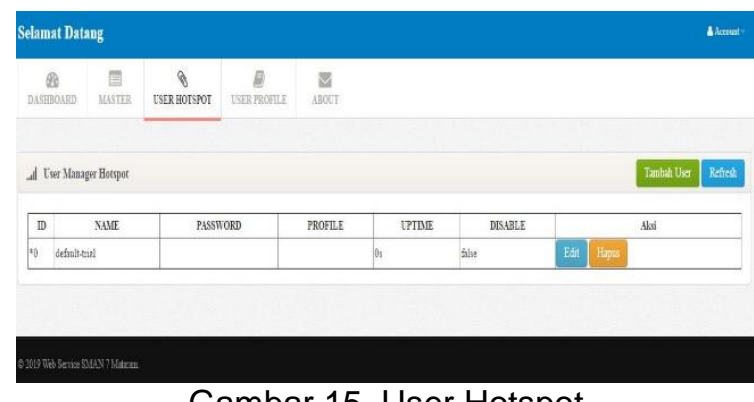

Gambar 15. User Hotspot

Tambah User kemudian admin menekan button tambah user

Isikan nama, password, profile dan tekan button simpan 


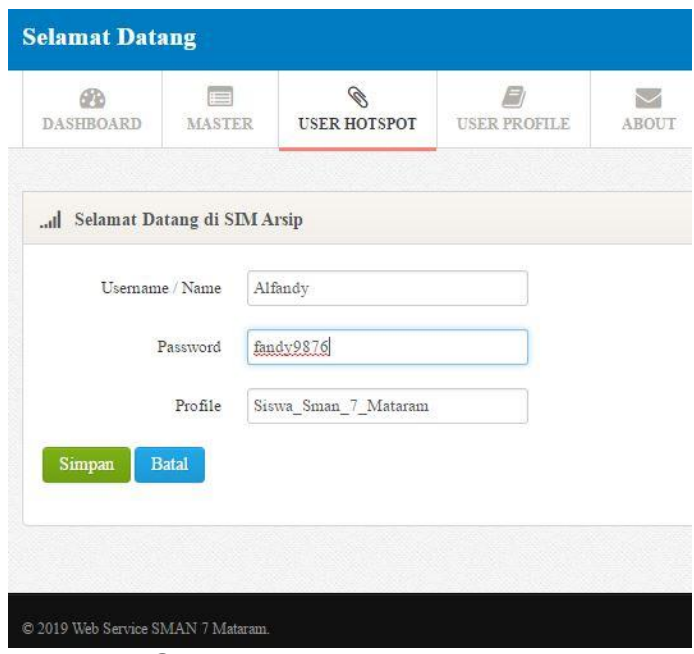

Gambar 16. Tambah User

Setelah berhasil maka akan tersimpan di halaman user hotspot. User yang tersimpan atas nama Fandy profile siswa dengan kecepatan upload dan download 256/256 dan atas nama Wahyu profile guru dengan kecepatan upload dan download 512/512. Admin juga dengan mudah mengubah maupun menghapus user hotspot yang sudah dibuat.

Berikut adalah user hotspot yang telah tersimpan:

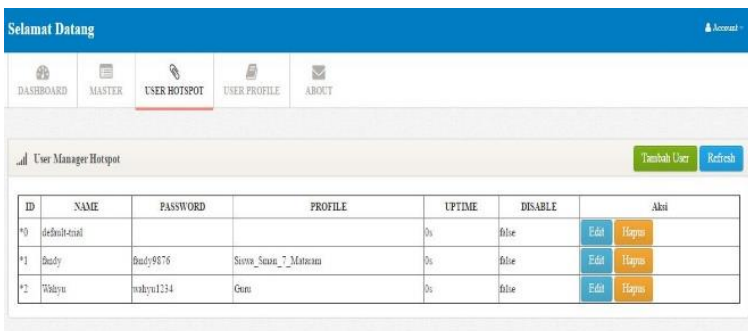

Gambar 17. User Hotspot Yang Tersimpan

\section{KESIMPULAN}

Kesimpulan yang didapat dalam pembahasan penelitian ini adalah sebagai berikut :

1) Bahwa dengan user manager kita dapat membuat sebuah jaringan hotspot menggunakan kabel atau nirkabel. Di user manager kita dapat membuat user atau voucher dengan profile sesuai kebutuhan. Disini kita juga dapat membatasi kuota upload download, dan membatasi kecepatan download upload.

2) Berdasarkan dari hasil implementasi, user siswa yang telah kita buat dapat login dan kecepatan yang didapat telah sesuai dengan profile-profile yang telah kita tentukan, yaitu dengan limitasi kecepatan 256k/256k dan untuk user guru dengan limitasi kecepatan 512k/512k.
3) Agar user manager yang dibuat dapat digunakan sebaik mungkin supaya fitur firturnya lebih di sederhanakan lagi agar bisa memantau jaringan dalam bentuk trafict yang lebih cepat.

\section{DAFTAR PUSTAKA}

[1] Muhammad, M., \& Hasan, I. 2016. Analisa dan Pengamanan Jaringan Wireless Berbasis Mikrotik Router os v.5.20 di Sekolah Dasar Negeri 24 Palu. Elektronik Sistem Informasi dan Komputer, 2: 12-13.

[2] Karim, R. 2016. Pentingnya Penggunaan Jaringan Wi-Fi dalam Memenuhi Kebutuhan Informasi Pemustaka Pada Kantor Perpustakaan dan Kearsipan Daerah Kota Tidore Kepulauan. ejournal "Acta Diurna" Volume V. No. 2.

[3] Frado, P.W. 2016. Analisis dan Perancangan User Manager pada Mikrotik Router dengan Sistem Pembelian Kredit Voucher. Jurnal SISFOKOM, Volume 05, Nomor 01.

[4] Riadi, I. (2011). Optimalisasi Keamanan Jaringan Menggunakan Pemfilteran Aplikasi Berbasis Mikrotik. JUSI Vol. 1, No. 1, 74.

[5] Ardiansa, M., Primananda, G., \& Hanafi, R. 2017. Manajemen Bandwidth dan Manajemen Pengguna pada Jaringan Wireless Mesh Network dengan Mikrotik. J. Pengemb. Teknol. Inf. dan Ilmu Komput., Vol. 1, No. 11, P. 11.

[6] Pamungkas, C.A. 2016. Manajemen Bandwith Menggunakan Mikrotik Routerboard Di Politeknik Indonusa Surakarta. J. Inf. Politek. Indonusa Surakarta, Vol. 1, No. 3, PP. 17-22..

[7] Faisal, I., \& Fauzi, A. 2018. Analisis QOS Pada Implementasi Manajemen Bandwith Menggunakan Metode Queue Tree dan PCQ (Per Connection Queueing). Jurnal Teknologi dan Ilmu Komputer Prima. Volume 1 Nomor 1, eISSN : 2541-2019.

[8] William J., \& Sri L.S. 2015. Sistem Informasi UKM Berbasis Website Pada Desa Sumber Jaya. Jurnal Informatics and Businnes Institute Darmajaya, Vol. 01, No. 1.

[9] Josi, A. 2016. Implementasi Framwork Boostrap Pada Website STMIK Prabumulih. Jurnal Mantik Penusa. Volume 20 No 1. ISSN:2088-3943.

[10] Sudarto, H.P. 2018. Perancangan Website Sebagai Media Promosi dan Informasi. Journal Of Informatic Pelita Nusantara. Volume 3 No 1. 
[11] EMS, Tim, 2014. Teori dan Paktik PHP MySQL Untuk Pemula. Jakarta: PT. Elex Media Komputindo.

[12] Abdulloh, Rohi, 2015. Web Programing is Easy. jakarta : PT Elex Media Komputindo.

[13] Hariyanto, Bambang. 2012. Esensi-Esensi Bahasa Pemograman Java: revisi keempat. Bandung : informatika

[14] Josi, A. 2017. Penerapan Metode Prototiping dalam Pembangunan Website Desa (Studi Kasus Desa Sugihan Kecamatan Rambang). JTI, Vol 9 No.1.

[15] Safitri, R. 2018. Simple Crud Buku Tamu Perpustakaan Berbasis PHP dan MySQL: Langkah-Langkah Pembuatan. Jurnal Tibanndaru. Volume 2 Nomor 2. 